\title{
Gestão ambiental integrada ao desenvolvimento sustentável: um estudo de caso em Passo Fundo (RS)*
}

\author{
Adriana Marques Rossetto** \\ Dora Maria Orth*** \\ Carlos Ricardo Rossetto****
}

SumÁRIO: 1. Introdução; 2. Sistema integrado de gestão do ambiente urbano; 3. Exemplificação em município de porte médio; 4. Conclusões.

SUMMARY: 1. Introduction; 2. Integrated urban environment management system; 3. Example in a midsize town; 4. Conclusions.

PAlAVRA S-CHAVE: gestão ambiental; desenvolvimento sustentável; urbanismo; sistema integrado de gestão do ambiente urbano.

KEY WORDS : environmental management; sustainable development; urbanism; integrated urban environment management system.

A acelerada urbanização transforma espaços naturais e interfere no meio ambiente, apresentando resultados desastrosos tanto nos ecossistemas quanto na qualidade de vida das pessoas. Este artigo propõe um novo ins-

* Artigo recebido em nov. 2004 e aceito em mar. 2006.

$* *$ Doutora em engenharia de produção e mestre em engenharia civil pela Universidade Federal de Santa Catarina (UFSC), graduada em arquitetura e urbanismo pela Universidade Federal de Pelotas (UFPEL), professora do Programa de Mestrado em Gestão de Políticas Públicas da Universidade do Vale do Itajaí (Univali). Endereço: Rua das Acácias, 121, bl. B3, ap. 402 — Carvoeira CEP 88040-560 — Florianópolis, SC, Brasil. E-mail: arossetto@ufp.br.

*** Doutora e mestre em geografia pela Université de Nancy II, França, graduada em arquitetura e urbanismo pela UFPEL, professora do Programa de Mestrado em Engenharia Civil e em Arquitetura e Urbanismo da UFSC. Endereço: Rua João Pio Duarte Silva, s/n, bloco A, CP 476 — Córrego Grande - CEP 88010-970, Florianópolis, SC, Brasil. E-mail: ecv1dmo@ecv.ufsc.br. **** Doutor e mestre em engenharia de produção pela UFSC, graduado em engenharia civil pela Pontifícia Universidade Católica de Pelotas, coordenador e professor do Programa de Mestrado Acadêmico em Administração da Univali. Endereço: Rua das Acácias, 121, bl. B3, ap. 402 — Carvoeira - CEP 88040-560 — Florianópolis, SC, Brasil. E-mail: rossetto@univali.br. 
trumento de gestão desses espaços que integra aspectos até agora fragmentados nas práticas administrativas e incorpora efetivamente as dimensões social e ambiental ao processo, direcionando os municípios para o desenvolvimento sustentável. O sistema utiliza ferramentas que viabilizam a participação comunitária e a visão estratégica no processo decisório, adaptando modelos de desenvolvimento utilizados na esfera empresarial, como o balanced scorecard (BSC) e a metodologia de análise ecossistêmica, que é capaz de elaborar um balanço ponderado multinível de índices obtidos em ações de monitoramento da região observada. Uma importante discussão proposta no artigo é a definição de indicadores de sustentabilidade para cada um dos aspectos abordados, considerando a necessidade de parâmetros que possam identificar o grau de sustentabilidade das cidades. O município de Passo Fundo, no Rio Grande do Sul (Brasil), serviu de piloto para a avaliação do instrumento proposto.

Environmental management integrated with sustainable development: a case study in Passo Fundo, RS, Brazil

Rapid urbanization has transformed natural spaces and interfered in the environment, with disastrous results both to the ecosystems and the quality of life of the people. This article proposes a new urban management system that integrates fragmented aspects in managerial procedures and really incorporates the social and environmental dimensions into the process, leading cities toward sustainable development. The system uses tools that allow community participation and strategic vision in the decision-making process. It also adapts development models used in business, such as the balanced scorecard and the ecosystemic analysis method, which can make a multilevel pondered balance of the indices obtained while monitoring the region under observation. An important discussion proposed by the article is that of defining sustainability indicators for each studied characteristic, considering the need for parameters that can identify the cities' sustainability level. The city of Passo Fundo, in the state of Rio Grande do Sul, Brazil, served as the pilot project to assess the proposed system.

\section{Introdução}

O ambiente urbano, entendido como uma organização social complexa regida pela incerteza e pela possibilidade - construído pelo conjunto de relações que se estabelecem entre suas partes —, não se restringe apenas às relações entre suas medidas e seus materiais. Como ele não vale por si próprio, seu valor ou significado surge em função das relações que estabelece entre o espaço e seus habitantes (Rheingantz, 1990). 
Variáveis sociais, econômicas, físico-espaciais e ambientais fazem parte desse complexo emaranhado de relações e demandas, o que requer habilidades de planejamento e gestão, de forma a gerar espaços urbanos democráticos, socialmente justos e com adequadas condições físico-ambientais.

Entretanto o que se observa no cenário brasileiro é uma rede urbana formada por cidades com características bastante diferenciadas, mas que, apesar de suas peculiaridades regionais e locais, abrigam, com maior ou menor intensidade, problemas intra-urbanos que afetam sua sustentabilidade, particularmente os decorrentes de dificuldades de acesso a terra urbanizada, déficit de moradias adequadas, déficit de cobertura dos serviços de saneamento ambiental, desemprego e precariedade de emprego, violência/precariedade urbana e marginalização social. A concentração física e o modelo de exclusão territorial que marcam o desenvolvimento de nossas cidades promovem e expõem a tragédia da concentração da renda nacional (Moraes, 2002; Bezerra e Fernandes, 2000; Rolnik, 2000; Rolnik e Cymbalista, 1997).

Esses desafios devem ser enfrentados, e um dos principais é o de buscar novos modelos de políticas públicas urbanas que combinem o esforço de crescimento econômico com as ações equilibradas para obtenção de condições dignas de vida para as populações, com redução nas taxas de degradação do meio ambiente. Repensar a gestão, o planejamento e a governabilidade urbana a partir de um considerável contingente de limitações não será tarefa das mais fáceis, entretanto precisa ser imediatamente assumida. Como solução possível para o enfrentamento dessas questões encontra-se a priorização na elaboração de instrumentos que viabilizem, na prática, as ações públicas para o desenvolvimento sustentável.

Assim, com o objetivo de auxiliar na instrumentalização das equipes técnicas das diversas secretarias das prefeituras e dos órgãos concessionários ou de prestação de serviços públicos, o presente artigo, resultado de estudos desenvolvidos pelos grupos de pesquisa em Políticas Públicas e Sustentabilidade (Programa de Mestrado em Gestão de Políticas Públicas) e pelo Núcleo de Gestão Ambiental e Social (Programa de Pós-Graduação em Administração) da Universidade do Vale do Itajaí (Univali), em conjunto com o grupo de pesquisa em Gestão do Espaço (Programas de Pós-Graduação em Engenharia de Produção, Engenharia Civil e Arquitetura e Urbanismo) da Universidade Federal de Santa Catarina (UFSC), propõe um instrumento para a gestão estratégica urbana. O sistema é baseado nos princípios da gestão democrática do Estatuto da Cidade e do desenvolvimento sustentável, atua a partir do nível de planejamento e formulação de políticas públicas, instrumentaliza a proposição de planos e auxilia na execução dos projetos. Outro aspecto importante do sistema proposto é a inclusão de mecanismos de avaliação e desempenho, essencial a qualquer processo de planejamento e gestão. 
O modelo, que se encontra mais bem especificado em Rossetto (2003), partiu da premissa de sustentabilidade adotada por Sachs (1986), que considera o equilíbrio entre crescimento econômico, eqüidade social e cuidado ecológico. A partir dos princípios e premissas adotados, adaptou ferramentas utilizadas na esfera empresarial para o meio urbano. A estrutura do instrumento inclui a inclusão efetiva da participação no processo de planejamento estratégico, a utilização de um balanced scorecard (BSC) para a gestão urbana, uma estrutura de indicadores direcionada para a sustentabilidade e a avaliação multinível. Essa última possibilita diversos níveis de análise e agrega informações de diferentes aspectos, uma das grandes dificuldades nos processos decisórios relacionados ao ambiente urbano.

\section{Sistema integrado de gestão do ambiente urbano}

Os preceitos que foram utilizados para a formulação do sistema integrado de gestão do ambiente urbano (Sigau) buscaram subsídios em três importantes marcos de discussão da política urbana e ambiental no Brasil: a Agenda 21 brasileira, o movimento pela reforma urbana e as diretrizes gerais estabelecidas no Estatuto da Cidade. Nos três casos, o debate público e a participação das entidades representativas tanto do setor público quanto da sociedade civil organizada deram autenticidade aos parâmetros que devem orientar a construção da política urbana em todas as instâncias do poder público.

Embora o trabalho tenha partido da idéia de criação de uma metodologia de apoio à decisão que utilizasse indicadores de qualidade ambiental para instrumentalizar as equipes técnicas das prefeituras na proposição de planos e projetos, a identificação de questões de abrangência maior que interferem diretamente nessas atividades fez com que a dimensão do trabalho fosse revista.

Metodologias de apoio à decisão utilizadas pelas equipes técnicas das prefeituras, mesmo que introduzidas as questões ambientais como proposto, não garantiriam que as mesmas fossem efetivadas, visto que o grande problema do processo decisório da gestão urbana está em equilibrar as tensões existentes entre os distintos atores que interagem no mesmo e, ao mesmo tempo, harmonizar a orientação política, os método utilizados e a consistência da base técnica que dá suporte à decisão.

De nada adianta melhorar o processo decisório somente do setor técnico, pois não se deve imaginar que o estado caótico da grande maioria de nossas cidades se deva ao despreparo dos profissionais desses escalões. O que se percebe é que, apesar de muitas vezes o trabalho ser de grande qualidade, o desconhecimento por parte dos decisores das implicações técnicas de cada 
projeto, ou o desconhecimento por parte dos técnicos dos verdadeiros objetivos dos decisores, faz com que o sistema como um todo se torne ineficiente. Exemplo disso é a formulação de leis urbanísticas tradicionalmente alteradas por agentes políticos, que desconhecem implicações técnicas (como, por exemplo, leis de alteração de uso e ocupação do solo) e que são os maiores fatores de impacto urbano e ambiental de médio e longo prazos.

Outra constatação é que, embora de indiscutível importância, o planejamento das cidades não tem, na maioria das vezes, cumprido seu papel, seja ele de caráter físico-territorial em sua versão convencional, marcadamente regulatória, seja na tipologia de planejamento estratégico mais difundida em nosso país, a mercadológica (Souza, 2003). Nem os próprios objetivos propostos pelos planos, questionáveis se analisados sob a luz dos movimentos recentes para mudanças nas políticas urbanas, são alcançados de forma satisfatória. Isso se deve ao fato de que os modelos existentes operam muito bem a formatação do processo, orientam a seqüência de etapas, mas não chegam a discriminar as metas e os objetivos específicos para cada setor ou área nem os procedimentos que cada envolvido no processo deve fazer para o alcance dos objetivos maiores. Por outro lado, não estabelecem os instrumentos e fontes de recursos (programas) para viabilização das ações e projetos previstos.

Dessa forma, mesmo que no nível operacional e no de formulação das políticas urbanas, ou seja, nas duas pontas do processo de gestão, a administração esteja bem direcionada, o que não é comum em municípios brasileiros, a seqüência de procedimentos para que haja continuidade não existe, fragmentando as ações públicas e tornando-as ineficazes.

Acrescente-se a isso o fraco controle social para monitoramento, cobrança e avaliação dessas ações do poder público, o que requer o aprimoramento da participação comunitária nos processos de gestão, através de mecanismos como criação de fóruns de discussão com caráter deliberativo (a exemplo do Conselho das Cidades em formação e de outros previstos no Estatuto da Cidade), e capacitação para a participação, o que demanda democratização das informações, quesito que vai ao encontro dos objetivos do sistema aqui proposto.

A proposta do presente artigo é unificar procedimentos que são reconhecidamente válidos, mesmo que utilizados na gestão de organismos com características distintas (empresas e órgãos públicos), e adaptá-los para utilização na administração de cidades, integrando e enfocando as questões relativas ao desenvolvimento sustentável e envolvendo todos os níveis da estrutura organizacional pública.

O Sigau foi estruturado para atuar nos três níveis da estrutura organizacional: 
v nível de formulação das políticas urbanas - composto por políticos, gestores, administradores, funcionários de escalões hierárquicos superiores dos órgãos públicos, empresários, sindicatos, associações civis, de classes, comunitárias e dos cidadãos em geral. Nesse nível a proposição é de introduzir na metodologia de planejamento estratégico mecanismos de efetiva participação popular, alterando a visão de cidade mercadoria para cidade fruto da construção coletiva. O instrumento foi denominado Planejamento Estratégico Participativo (PEP);

v nível de elaboração de planos e propostas - composto por gestores, administradores, políticos, funcionários de escalões hierárquicos superiores dos órgãos públicos e corpo técnico. Para esse nível foi adaptado um instrumento utilizado pela esfera empresarial para a efetivação das estratégias oriundas do planejamento estratégico, o BSC (Kaplan e Norton, 1997).

、 nível de elaboração de projetos e execução de ações - composto por corpo técnico e funcionários dos escalões operacionais. Para auxiliar a execução dos planos e projetos resultantes da aplicação das etapas anteriores, dois instrumentos de apoio à decisão foram incorporados ao processo. Um voltado para a escolha de melhores opções de ação, o Método Aditivo Linear (MAL) (Bramont, 1996), e o outro destinado à avaliação e ao monitoramento do desempenho dos distintos aspectos do desenvolvimento urbano, baseado em metodologia utilizada pelo Programa das Nações Unidas para o Meio Ambiente (Unep) e pela Organização das Nações Unidas para a Educação, Ciência e Cultura (Unesco) (1987) para avaliação do desempenho ambiental de bacias hidrográficas. Esse último instrumento possibilita também a geração de cenários.

O modelo permite a transição do caráter das ações de forma compatível com a essência de cada uma das etapas do processo, sendo a primeira essencialmente política e a última, eminentemente técnica (figura 1).

O Sigau é composto por três fases e 18 etapas. A primeira fase compreende o planejamento da cidade de forma integrada, estratégica e participativa e foi denominada PEP. Essa fase vai desde a organização do processo, o diagnóstico e a análise da cidade, até a definição de um modelo de desenvolvimento desejado pela comunidade e as estratégias para atingir o cenário desejado.

A segunda fase busca viabilizar a efetivação das estratégias definidas pela comunidade na primeira fase, utilizando um BSC e criando uma estrutura adequada, uma linguagem comum, com indicadores para informar e possibilitar um processo participativo. Nela encontram-se a definição das perspectivas a serem observadas na implementação das estratégias, a definição dos fatores críticos de cada uma das perspectivas, a identificação da relação de causa e efeito 
entre elas, a formulação de propostas, a indicação de objetivos e metas, a definição de indicadores para acompanhamento e a identificação das fontes de financiamento para suporte às ações.

Figura 1

Inter-relação do Sigau com o processo decisório

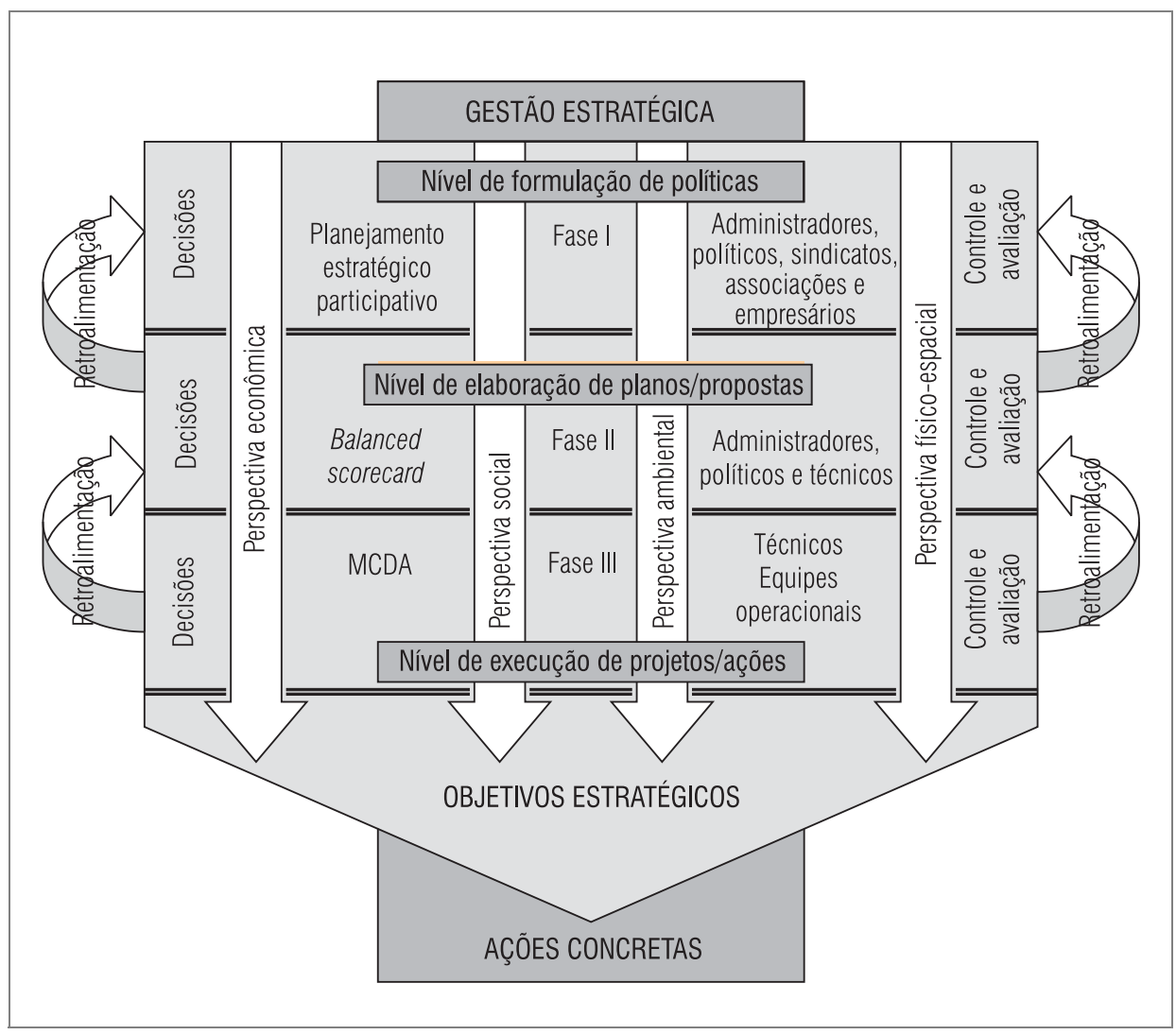

Na última fase são utilizadas Metodologias Multicritérios de Apoio à Decisão (MCDA) que auxiliam as equipes técnicas a melhorar o processo decisório apresentando e priorizando os projetos que cumpram os objetivos de curto e longo prazos definidos na fase anterior. Esses instrumentos permitirão que, de forma gradual, estratégias, objetivos e metas sejam traduzidos em planos e projetos e operacionalizados dentro de uma única linha de ação. A estrutura do Sigau pode ser mais bem compreendida na figura 2. 
Figura 2

\section{Estrutura do Sigau}

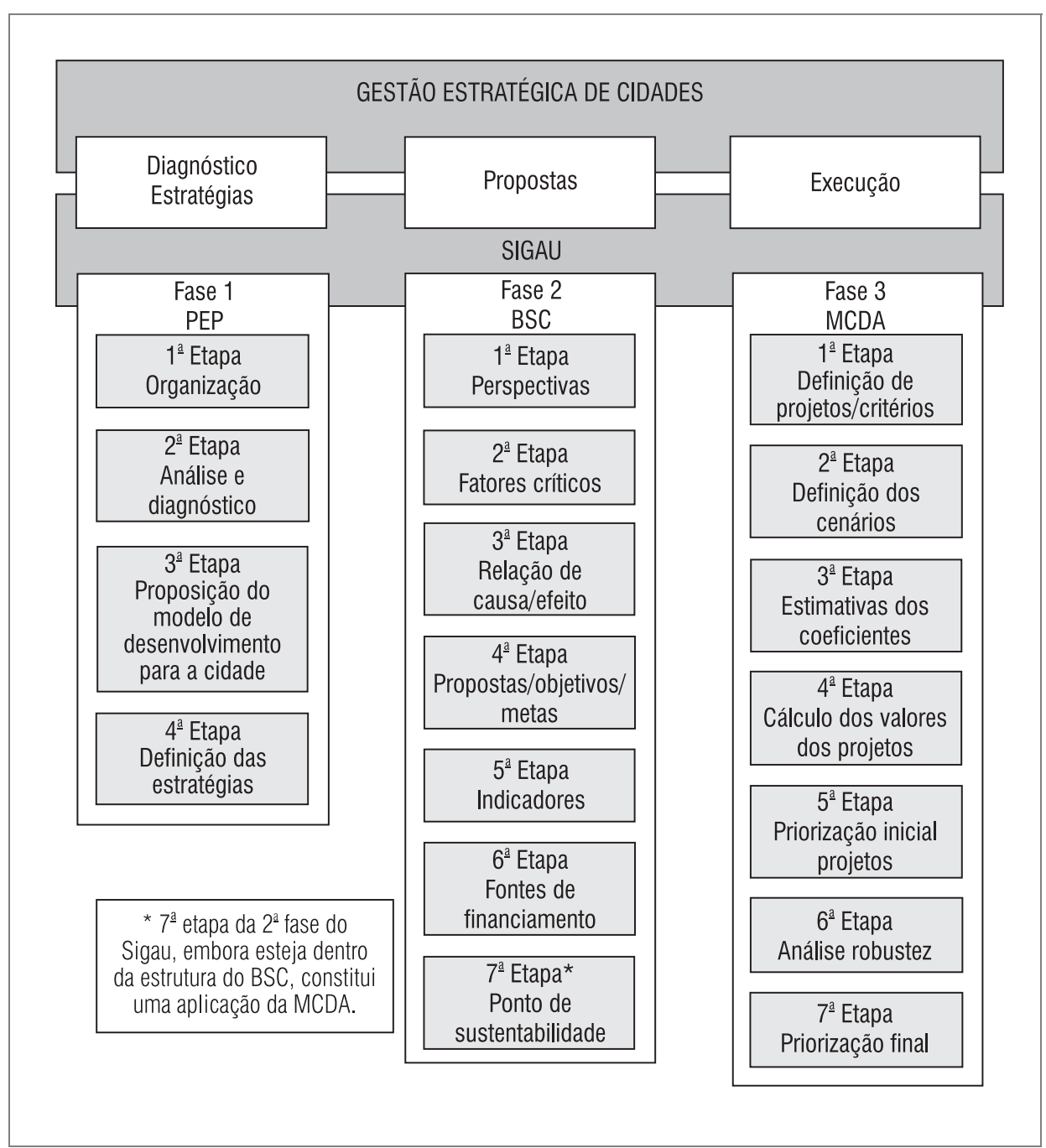

O sistema proposto engloba o planejamento e a gestão urbana, que, embora indissociáveis, referem-se a momentos distintos, pois, enquanto o planejamento trata do futuro, a gestão trabalha com o presente, com a execução dos anseios colocados no planejamento.

Cada um dos instrumentos será descrito a seguir. 


\section{Planejamento estratégico participativo}

Neste artigo, desvincula-se do termo planejamento a idéia do planejamento normativo de caráter regulatório (incluindo nesse perfil os planejamentos físico-territoriais clássicos e o planejamento sistêmico) que, segundo Brindley (1989), reinou durante muito tempo como estilo central na ideologia da profissão de planejamento, e busca-se uma postura mais crítica, na qual o planejamento e a gestão urbana sejam utilizados como ferramentas de promoção do desenvolvimento socioespacial.

Já em relação à conotação estratégica, a proposta parte de uma visão diferenciada de planejamento estratégico em que a necessidade de pensar os destinos da cidade em longo prazo, traçar estratégias maiores e buscar o consenso da comunidade em torno desses objetivos permanece. Entretanto a visão mercadológica (utilizando a terminologia de Brindley (1989) — planejamento subordinado às tendências do mercado [trend planning]; planejamento de facilitação [leverage planning]; e planejamento de administração privada [private-management planning], e que no Brasil ficou conhecido como "urbanismo de resultado"), normalmente associada ao termo estratégico, no qual as cidades são tratadas como mercadorias, a competição entre cidades é incentivada e o objetivo maior está voltado ao desempenho econômico, é descartada e substituída pelos objetivos do desenvolvimento sustentável.

O modelo traz conceitos e procedimentos do planejamento estratégico clássico utilizado no meio empresarial e em cidades, mas sua essência é alterada à medida que assume um caráter efetivamente participativo, no qual a população não somente é consultada, mas delibera sobre assuntos de seu interesse. Procura-se aproximar da linha do "planejamento estratégico situacional" proposto por Matus (1996) e que, conforme Souza (2003), no Brasil é assumido na proposta de um "planejamento politizado", inspirado no ideário da reforma urbana. Dessa forma, o planejamento se transforma em uma construção coletiva, mas mantém sua função principal, que é a de direcionar as ações da comunidade para objetivos comuns.

A questão da participação é tratada pelo modelo de forma a ampliar suas aplicações, extrapolando a alçada dos orçamentos participativos. Buscam-se introduzir diversas esferas de participação popular, preconizadas no Estatuto da Cidade, defendendo o fortalecimento das entidades representativas dos diversos setores e, através delas, a participação dos cidadãos, desde as etapas de formulação das políticas públicas e de planejamento das cidades. 
O PEP foi idealizado incluindo o enfoque da participação popular de forma efetiva, utilizando instrumentos disponíveis na legislação vigente (em especial o Estatuto da Cidade no qual estão previstas as Conferências das Cidades, as Audiências Públicas e a formação de Conselhos das Cidades) e propondo caráter deliberativo aos fóruns em suas distintas instâncias, fortalecendo entidades representativas e associações de classe. Entretanto não se pode menosprezar nem a dimensão política do processo de planejamento urbano e tampouco a dimensão técnica (Souza, 2003). Dessa forma, a proposta inclui instrumentos de análise e diagnóstico que garantem um enfoque integrado e coordenado do planejamento da cidade, visando garantir uma visão global de sua problemática e a formulação de um modelo de desenvolvimento consistente. O fluxograma de funcionamento e hierarquia do PEP está demonstrado na figura 3.

Figura 3

Fluxograma do PEP

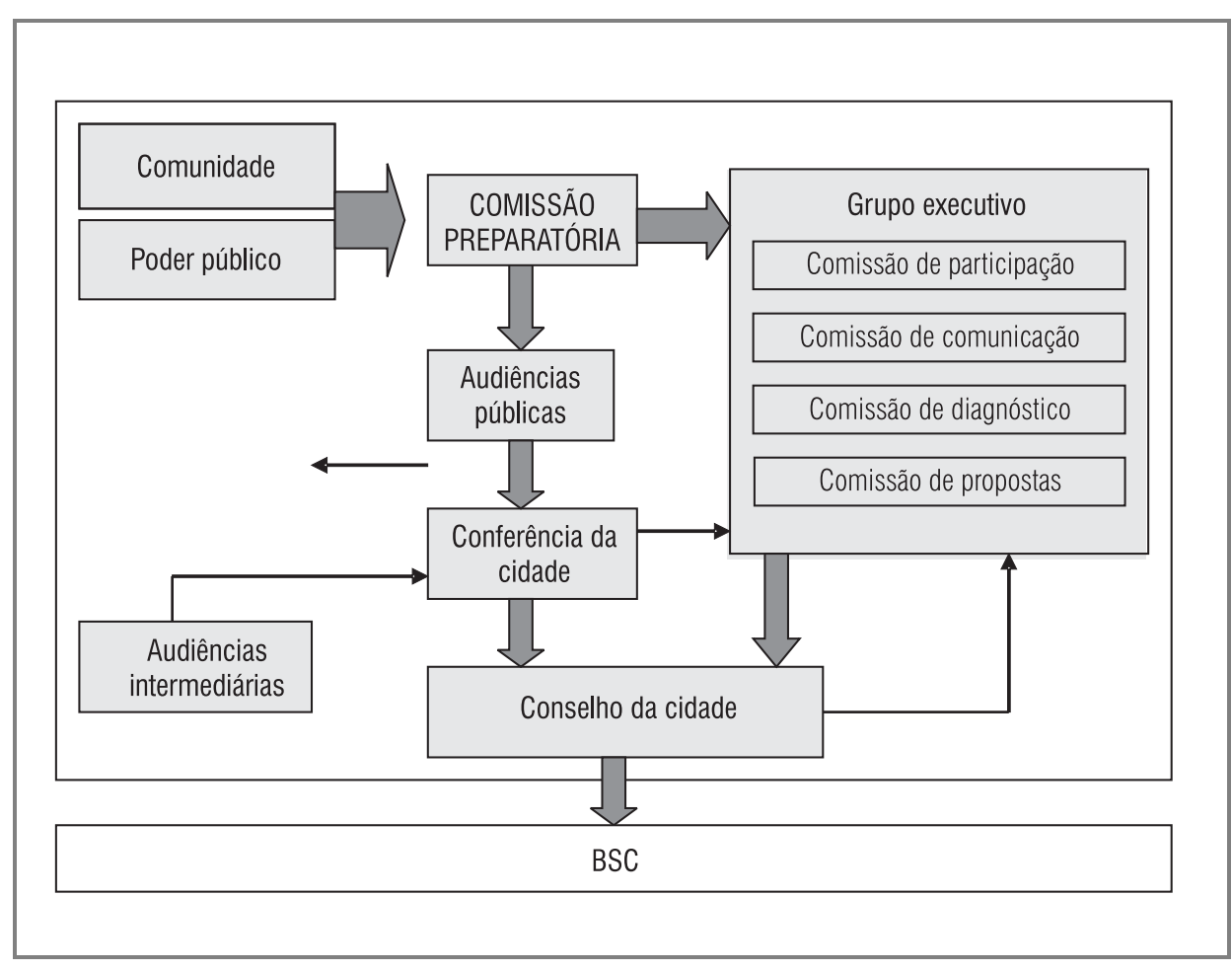


Todas as etapas seguem a premissa da participação e estão mais bem detalhadas em Rossetto (2003). Elas incluem a organização do processo, a análise e o diagnóstico urbano, a proposição do modelo de desenvolvimento para a cidade e a definição das estratégias.

Tendo em vista que o planejamento sempre deverá considerar a situação presente, o sistema proposto foi formulado de maneira que as informações geradas pelas diversas fases e etapas sejam as que retroalimentam todo o processo. Assim, as informações do PEP alimentarão as ações do BSC, que, ao mesmo tempo, fornecerá as informações para o processo decisório das equipes técnicas, o qual retroalimentará o PEP, o mesmo ocorrendo com o BSC em relação ao MCDA e assim por diante. Desse modo, a formulação das estratégias não fica restrita a um único momento, sendo que as estratégias que serão definidas nessa etapa posteriormente serão desdobradas em metas (fase do BSC) projetos e ações estratégicos (fase do MCDA). A figura 4 demonstra a interligação entre as etapas e a influência na formulação das estratégias.

\section{Balanced scorecard}

O segundo instrumento, um modelo BSC com estrutura similar à do proposto por Kaplan e Norton (1997) e utilizado no ambiente corporativo, integra as medidas derivadas das estratégias das empresas, observando outras perspectivas que não somente a financeira.

Na etapa do BSC as estratégias passam a ser trabalhadas em distintas perspectivas. A partir dos princípios de política urbana adotados como pressupostos do trabalho, o mesmo contemplou as perspectivas social, ambiental, físico-espacial e econômica, consideradas de fundamental importância para a avaliação do desempenho das cidades e que, se observadas, garantem equilíbrio entre aspectos definidores da sustentabilidade urbana.

A medição do desempenho será feita da mesma forma que no modelo de BSC proposto por Kaplan e Norton (1997), entretanto com outras perspectivas (figura 5).

Embora muitos aspectos estejam presentes e interajam com mais de uma perspectiva, por questões didáticas e operacionais cada uma delas será observada a partir de determinados aspectos que serão a seguir especificados. 
Figura 4

\section{Interligação entre as etapas e a influência na formulação das estratégias}

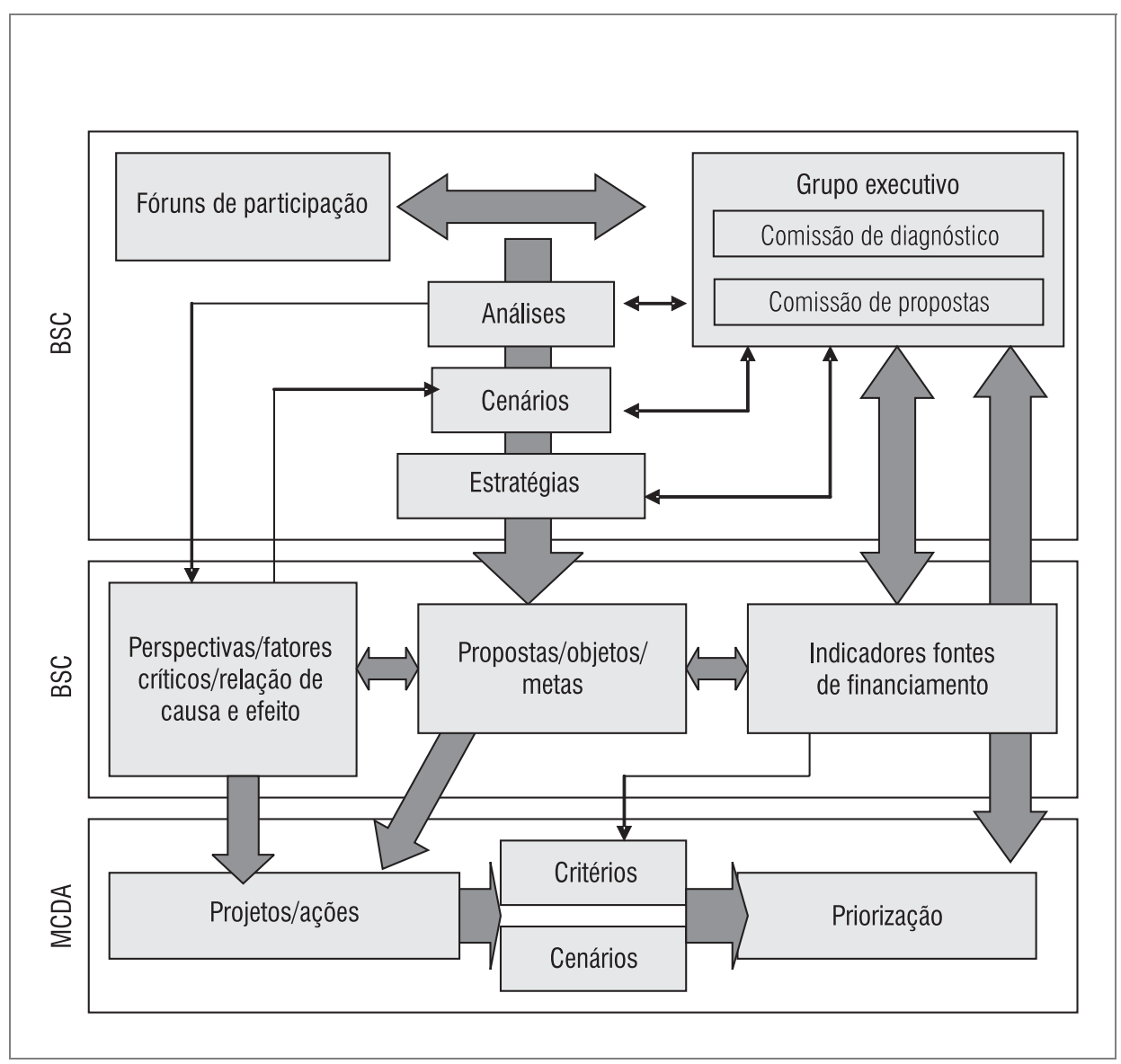

v Perspectiva social: os aspectos abordados nessa perspectiva relacionam-se às questões de saúde, longevidade, educação, cultura, lazer, esporte, acesso a serviços públicos, participação política, justiça social, segurança, cidadania, infância, emprego, habitação, transporte público, nível de renda, alimentação, marginalização e outros que digam respeito à qualidade de vida da população.

v Perspectiva ambiental: os aspectos abordados na perspectiva ambiental relacionam-se às questões de meio ambiente, equilíbrio ecológico, condição dos recursos naturais, condições climáticas, preservação de espécies (animais e vegetais), poluição (sonora, do ar, do solo), utilização de energias 
renováveis, geração e tratamento de lixo, condição de cursos d'água, preservação de matas ciliares e outros que digam respeito à forma como o meio urbano afeta o meio ambiente e impacta a natureza.

v Perspectiva físico-espacial: os aspectos abordados nessa perspectiva relacionam-se a questões de uso e ocupação do espaço urbano, densidades, sistema viário, pavimentações, poluição visual, infra-estrutura para água, luz, telefone e saneamento básico, problemas de enchentes, grau de impermeabilização do solo, arborização, insolação e ventilação dos recintos urbanos, percepção dos espaços, áreas degradas, patrimônio histórico e outros que digam respeito à qualidade física e espacial do ambiente urbano.

v Perspectiva econômica: os aspectos abordados aqui relacionam-se às questões de produto interno bruto (PIB), investimentos públicos/privados, desempenho dos setores, renda per capita, arrecadação, orçamento municipal, macroeconomia, economia regional, nível de emprego e outros que digam respeito à geração de recursos para melhorar a qualidade de vida da população e do ambiente urbano.

Figura 5

\section{Estrutura do BSC para ambientes urbanos}

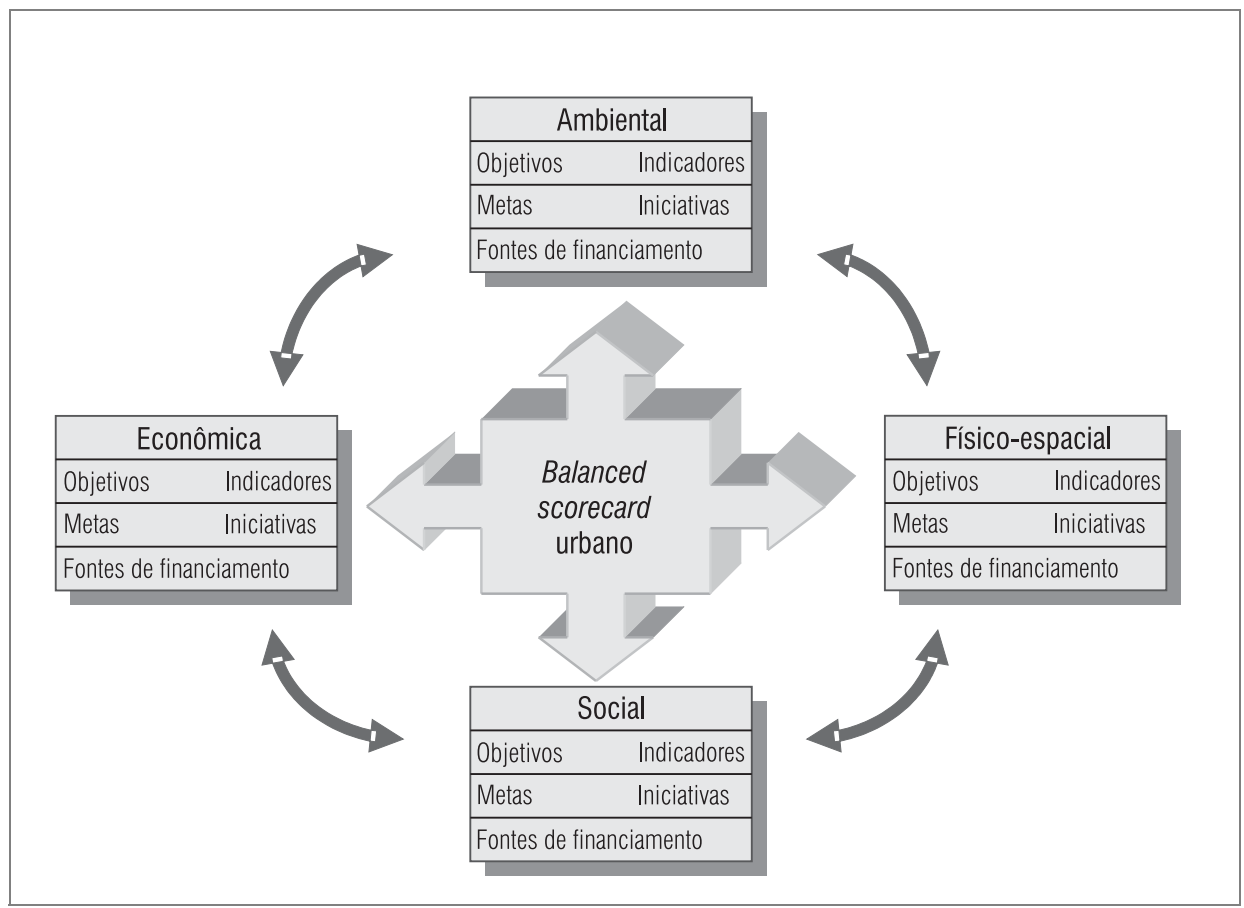


Tendo-se em vista a abrangência das perspectivas e que o enfoque principal do trabalho é o desenvolvimento sustentável, ou seja, que exista equilíbrio entre o desenvolvimento de cada uma, e considerando-se que a função do Estado é preservar o direito de todos e a justiça social, compensando os pontos mais frágeis do tecido socioeconômico-ambiental da estrutura urbana, foram identificados alguns fatores críticos cujos desempenhos condicionam o desenvolvimento sustentável.

\section{Identificação dos fatores críticos}

A escolha dos fatores críticos foi baseada nos princípios que nortearam a formulação do modelo, utilizando o diagnóstico apresentado pela Agenda 21 brasileira e buscando minimizar as situações que não se enquadram como desejáveis nas linhas da atual política urbana e fomentar a utilização dos novos instrumentos propostos pelo Estatuto da Cidade.

Além da identificação dos aspectos-chave a serem trabalhados no planejamento e na gestão para a efetivação das estratégias de desenvolvimento, os fatores críticos, depois de desmembrados em aspectos pontuais, facilitam a escolha dos indicadores. Os fatores críticos escolhidos para cada perspectiva são relacionados a seguir.

v Perspectiva social: inclusão territorial (acesso à moradia urbanizada, de forma regular, em locais adequados e integrados à malha urbana, ao transporte coletivo e ao saneamento básico); estrutura social (discriminação por racismo, sexo, idade, renda, emprego, opção sexual; trabalho infantil; crianças e adolescentes marginalizados; idosos abandonados; injusta distribuição de renda); educação (acesso ao ensino básico e profissionalizante em idade adequada, a cursos de segundo e terceiro graus públicos e a cursos que melhorem a chance no mercado de trabalho); cultura (acesso a livros, revistas e jornais ou outros meios de comunicação; a espetáculos de teatro, dança, música e produções cinematográficas; a exposições de artes; e apresentações de trabalhos científicos. Nesse fator crítico, entretanto, também é importante o acesso ao ensino e ao desenvolvimento de aptidões em todas essas áreas); saúde (acesso a atendimentos de emergência, próximo e em condições adequadas, hospitalar, quando necessário; a atendimento preventivo e especializado; a atendimento odontológico; a medicamentos de uso comprovadamente necessário; baixas taxas de mortalidade infantil; altos índices de longevidade; erradicação de doenças epidêmicas e de vetores); lazer (acesso a áreas verdes, a equipamentos urbanos destinados à diversão e a manifestações de cultura e de patriotismo, como desfiles e comemora- 
ções; a locais de beleza cênica destinados à contemplação; a locais de recursos naturais de patrimônio público como praias, rios, lagos); esporte (acesso a áreas esportivas, treinamento especializado, competições municipais e intermunicipais); segurança pública (significa: mobilidade na cidade independente de local ou horário; proteção à propriedade privada; pronto atendimento policial, de bombeiros e da Justiça; estrutura carcerária compatível e adequada; controle do tráfico de drogas e da prática de receptação); participação política (comunidade com poder deliberativo sobre as diversas escalas espaciais da participação; autonomia da sociedade civil em relação às forças políticas; existência de mecanismos para redução da desigualdade de condições para participação; necessidade de desenvolvimento de capacidades técnicas, organizacionais e da sociedade civil para a participação).

v Perspectiva ambiental: preservação dos ecossistemas (manutenção de ecossistemas importantes em quantidade suficiente para manter a biodiversidade do planeta e as condições de vida tanto na escala local, quanto regional e global) e de sua qualidade (manutenção das condições adequadas dos ecossistemas preservados: qualidade dos recursos naturais).

v Perspectiva físico-espacial: organização físico-espacial (significa a existência de plano diretor, leis de usos e ocupação, equilíbrio na distribuição espacial da população, preservação de áreas verdes, inexistência de vazios urbanos e de ocupações ilegais e em áreas de risco, desenvolvimento institucional na área das políticas urbanas); abrangência e qualidade da infra-estrutura (abastecimento de água, coleta e tratamento de esgoto e de lixo, oferta de energia elétrica, abrangência da rede viária e pavimentação de vias, organização do sistema de trânsito municipal, calçadas; drenagem urbana adequada); qualidade dos ambientes urbanos (significa oferta compatível de equipamentos de saúde, educação, lazer, segurança, mobiliário urbano, áreas verdes, espaços diversificados em termos de privacidade e de escala); conforto do usuário (significa manutenção de condições ambientais dentro das zonas de conforto para seres humanos com relação a temperatura, ventos, insolação, ruídos, odores, umidade); percepção ambiental agradável com compatível grau de permeabilidade, identidade local, paisagem cênica, perspectivas visuais, harmonia de conjunto).

v Perspectiva econômica: finanças municipais (avaliadas através da arrecadação municipal; do percentual de investimento em obras destinadas a cada uma das perspectivas; do retorno do investimento público pela valorização fundiária) e economia local (avaliada através do PIB, do nível de emprego, do grau de industrialização, da renda per capita; da arrecadação oriunda de atividades turísticas). 


\section{Relação de causa e efeito principal}

No caso da aplicação do BSC para o meio urbano, o fim maior a ser buscado é o desenvolvimento sustentável, que será atingido quando os objetivos e metas das demais perspectivas também o tenham sido. Ao contrário da área empresarial, a perspectiva econômica não é o principal objetivo das cidades, sendo uma das finalidades-meio para que seja atingido o objetivo-fim do desenvolvimento sustentável.

A perspectiva econômica dará suporte para os investimentos públicos e privados e viabilizará a realização das estratégias das demais perspectivas através da destinação de recursos de forma equilibrada.

A perspectiva físico-espacial, na qual estão contidas as questões de infraestrutura, de conforto aos usuários dos ambientes e de suporte às atividades da população, depende do desempenho da perspectiva econômica e interfere no desempenho tanto da perspectiva social quanto da ambiental. Através dessa perspectiva as obras de infra-estrutura necessárias ao correto funcionamento da cidade, a definição de seus usos e forma de ocupação e o controle das condições de conforto viabilizarão a efetivação das atividades e relações sociais em maior ou menor grau de conformidade com os princípios norteadores das políticas urbanas. As relações com o meio ambiente também serão afetadas pelo grau de urbanização e pelas práticas e técnicas utilizadas nesse processo.

As perspectivas social e ambiental posicionam-se no topo da estrutura de causa e efeito e se relacionam de forma horizontal, sendo que ambas podem ser causa ou efeito uma da outra, dependendo do fenômeno observado. Entretanto as quatro perspectivas são objetivos-meio para o objetivo maior, que é o desenvolvimento sustentável da cidade. A figura 6 mostra a cadeia de causa e efeito do BSC proposto, exemplificando alguns dos fatores críticos de cada perspectiva.

\section{Sistema de indicadores para o desenvolvimento sustentável}

Para este artigo, a escolha dos indicadores que farão parte do modelo proposto foi feita com base nas abordagens da Organização para Cooperação e Desenvolvimento Econômico (OECD, 1993) e da Environmental Protection Agency (EPA, 1995), que se têm constituído em marcos direcionadores, em especial para a área ambiental. O sistema conceitual de indicadores proposto e adotado pelos países da OCDE baseia-se no entendimento comum de seus pressupostos, servindo como referência e sendo o mais adotado atualmente no mundo. O sistema 
"pressão-estado-resposta", como é denominado, está baseado no conceito da causalidade (OECD, 1993):

Atividades humanas exercem pressão sobre o meio ambiente e mudam sua qualidade e a quantidade dos recursos naturais (estado). A sociedade responde a essas mudanças através de políticas ambientais, econômicas e setoriais (resposta social). (...) Esses passos formam parte de um ciclo (política) ambiental que inclui a percepção dos problemas, a formulação de políticas, o monitoramento e a avaliação política.

Figura 6

\section{Relação de causa e efeito do BSC para gestão urbana}

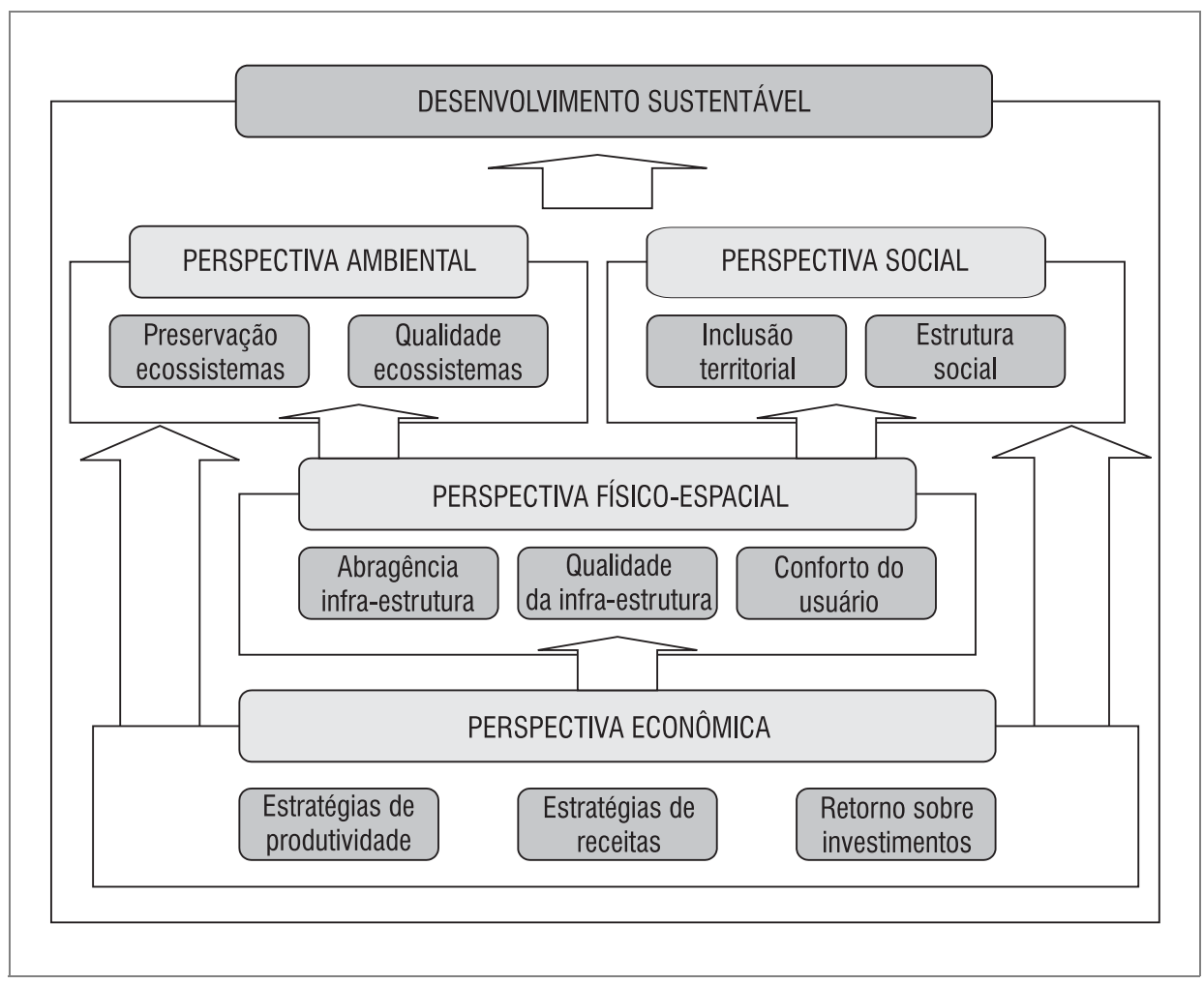

Os indicadores na estrutura de sistema pressão-estado-resposta estão representados na figura 7 . 
Figura 7

Sistema pressão-estado-resposta

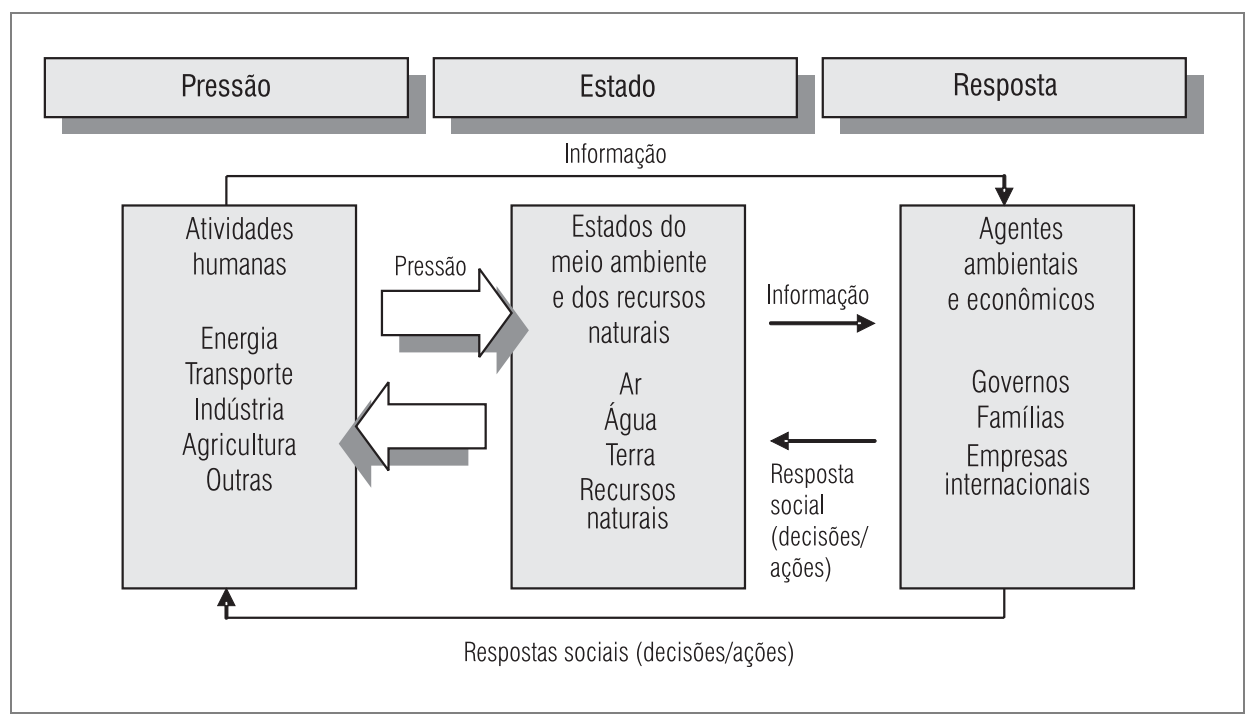

Fonte: OECD, 1993

A partir dos fatores críticos foram identificados indicadores essenciais que retratam o panorama de cada fator crítico em relação aos aspectos que exercem pressão sobre a atividade observada; ao estado, ou seja, à situação em que se encontra esse fator; e em relação às respostas que estão sendo dadas pelo poder público ou pela comunidade através de políticas e programas.

De fundamental importância para a compreensão da proposta é que os indicadores escolhidos são frutos de um primeiro processo de aproximação, tendo em vista a abordagem construtivista do sistema e o caráter de participação que se busca inserir no processo de planejamento e de gestão. Um dos conceitos adotados pelo trabalho é a estratégia utilizada pela Environmental Monitoring and Assessment Programs (Emap) (EPA, 1995), que prioriza a natureza interativa entre os grupos envolvidos no uso dos indicadores e no processo de desenvolvimento dos mesmos, demonstrando, com isso, a necessidade continuada de reavaliar e desenvolver, sistematicamente, indicadores apropriados aos usuários.

Devido à abrangência dos aspectos observados, foi proposta uma gama bastante extensa de indicadores, os quais podem ser encontrados em Rossetto (2003). 


\section{Avaliação integrada da sustentabilidade urbana}

A prática tem mostrado que a ação de medir auxilia tanto os decisores quanto os cidadãos comuns a conceitualizar objetivos, estudar alternativas e operacionalizar a implementação de políticas norteadoras do desenvolvimento humano. A abordagem setorial, entretanto, compõe-se de uma barreira para o desenvolvimento de indicadores sistêmicos e de índices de agregação em ordem superior, a partir dos mesmos (Bollmann, 2001; Bollmann e Marques, 2001).

No caso do ambiente urbano, o entendimento das alterações nele provocadas tem sido historicamente abordado sob o ponto de vista reducionista, sendo estudados os fenômenos isoladamente ou, no máximo, agrupados por campo do conhecimento. Nesse sentido, uma abordagem proposta pelo Scientific Expert Group, grupo de trabalho de projeto da Unep/Unesco para a avaliação integrada de bacias hidrográficas, apresenta uma estratégia de gestão ambiental baseada na análise ecossistêmica, que é capaz de elaborar um balanço ponderado multinível de índices obtidos em ações de monitoramento da região observada (Unep/Unesco, 1987).

Em uma análise efetuada sobre a metodologia, Bollmann (2001) considera que a grande inovação do modelo consiste em agregar indicadores de variáveis pertencentes a distintos grupos do conhecimento, através de aproximações sucessivas, até gerar um único indicador de desempenho geral da área.

A aplicação deste instrumento, com base no modelo proposto pela Unep/Unesco (1987) e adaptada para o sistema de indicadores proposto por Rossetto (2003), permite uma apreciação multidimensional do desenvolvimento municipal, fornecendo análises mais abrangentes do impacto das distintas ações e fatos urbanos em cada um dos fatores críticos, nas perspectivas separadamente ou na cidade como um todo.

O método baseia-se explicitamente no conceito da "programação por compromisso", que faz parte de um grupo de metodologias multicritério de apoio à decisão conhecido como "de articulação progressiva das preferências do gestor". A composição dos indicadores é feita a partir da normalização dos resultados entre os valores 0 e 1 e as formulações matemáticas e as rotinas operacionais foram mantidas iguais ao modelo Unep/Unesco (1987). A estrutura de composição multinível é utilizada, tendo sido alteradas a quantidade de níveis e a divisão dos sistemas observados. O modelo Unesco considera o meio ambiente fonte de recursos para o sistema socioeconômico.

A metodologia propõe gerenciar ou monitorar um sistema através da quantificação dos indicadores e da definição do estado atual, da melhor e da 
pior situação que estiver sendo medida pelo indicador. Assim eles se tornam valores-padrão que medem o relacionamento entre os valores desejados e os observados pelas medições no sistema. Nessa proposta, a composição dos indicadores é feita a partir da agregação dos indicadores básicos de cada fator crítico e, após, entre as perspectivas social e econômica e físico-espacial e ambiental. Esses dois indicadores compostos geram o indicador de sustentabilidade da cidade. Essa etapa permitirá que sejam também efetuadas simulações de situações, arbitrando resultados para indicadores ou para qualquer um dos níveis de composição (figura 8).

Por exemplo: os indicadores de moradia urbanizada, transporte público e saneamento básico são agregados, fornecendo um indicador de inclusão territorial. Esse, por sua vez, é agregado aos indicadores de estrutura social, educação, cultura, saúde, esporte, lazer, segurança pública, participação popular, já agregados em seus itens básicos, fornecendo o grau de sustentabilidade da perspectiva social. Esse indicador será agregado ao indicador econômico, gerando um indicador de terceiro nível. O mesmo processo é feito para os indicadores das perspectivas ambiental e físico-espacial, sendo que o último nível de agregação será o que inter-relacionará os indicadores de terceiro nível e fornecerá o ponto de sustentabilidade da cidade.

Embora seja uma formulação matemática e ofereça parâmetros numéricos para a avaliação dos diversos níveis, a essência do modelo ainda é qualitativa, pois os resultados são diretamente dependentes das decisões relativas à definição de parâmetros e pesos de importância para cada item, decisões essas que antecedem a aplicação das rotinas matemáticas. Sua métrica baseiase em uma noção geométrica de "melhor", devendo ser definido para cada um dos indicadores básicos o que a equipe de trabalho ou a comunidade considera a situação ideal e o que considera a pior situação possível. Outro momento em que a linha de atuação política irá direcionar os resultados é na atribuição dos pesos de cada item nos níveis de agregação. Desse modo, se os gestores e a comunidade considerarem que a questão social possui maior relevância que a ambiental, ou que a físico-espacial possui a mesma importância que a econômica, os pesos para avaliação da sustentabilidade foram estipulados seguindo essa preferência.

Cabe lembrar que, para ser considerado sustentável, segundo definição que norteia o presente trabalho, o desenvolvimento deve apresentar equilíbrio entre as quatro perspectivas escolhidas. Assim, os pesos atribuídos procuraram sempre imprimir um caráter de igualdade de relevância entre elas.

O modelo fornece o ponto de sustentabilidade para cada uma das etapas intermediárias e ainda viabiliza a geração de cenários e simulações para auxiliar a gestão e o planejamento urbano. 
Figura 8

Modelo de gerenciamento do grau de sustentabilidade da cidade

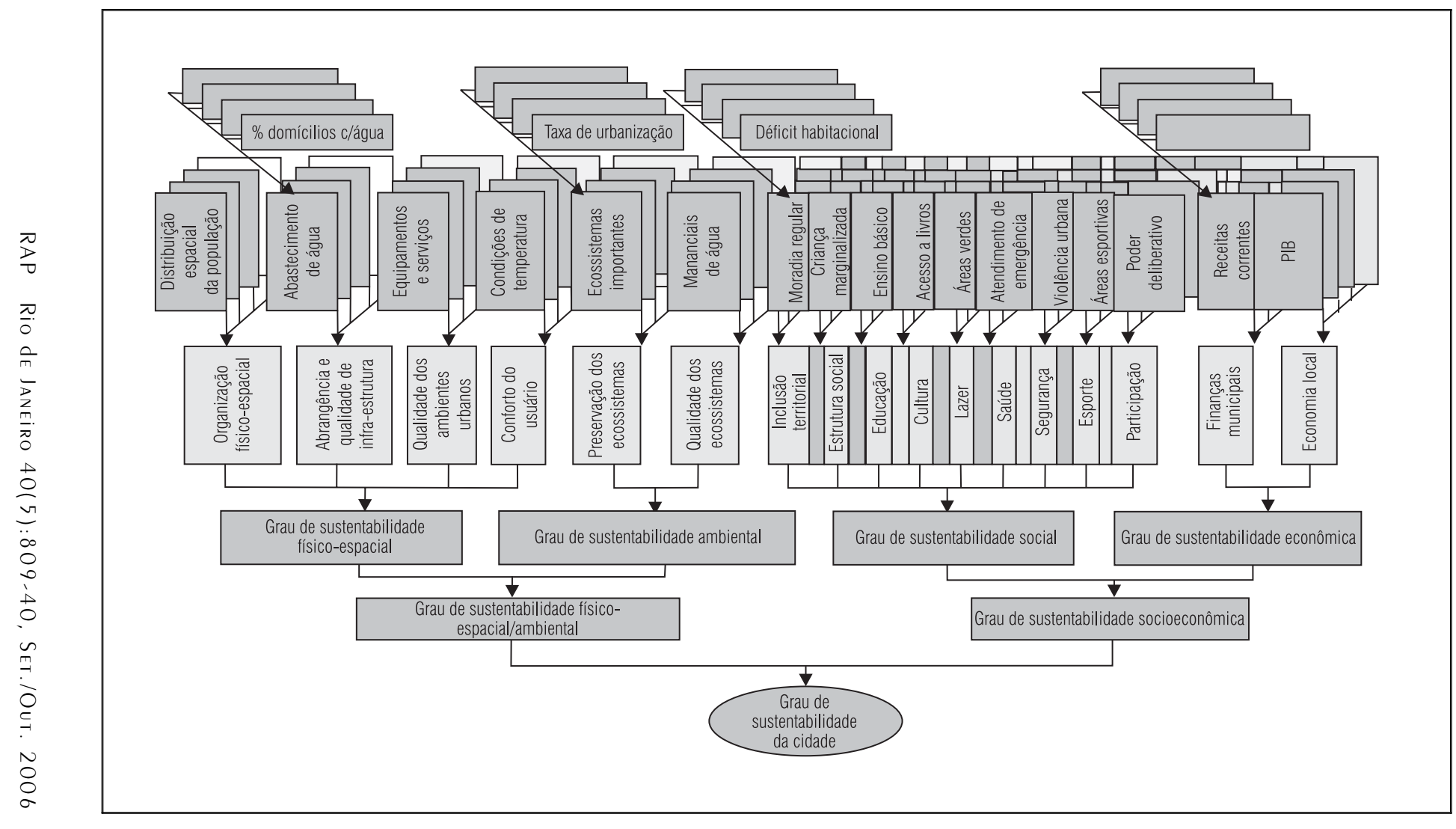




\section{Método aditivo linear}

O quarto instrumento que compõe o Sigau é uma metodologia de apoio à decisão para a qual foi utilizado um método desenvolvido por Bramont (1996) em sua tese de doutoramento na Universidade Federal de Santa Catarina (UFSC) denominado Método Aditivo Linear (MAL). Cabe salientar que, como os demais instrumentos, a estrutura proposta permite que os modelos possam ser alterados ou substituídos por outros que desempenhem o mesmo papel e que se adaptem a situações específicas. Ou seja, outra metodologia MCDA poderá ser utilizada desde que incorpore os indicadores utilizados para o acompanhamento das metas estipuladas no BSC.

Este método foi escolhido em virtude de sua estrutura ser extremamente simples, o que viabiliza que municípios de qualquer porte possam utilizálo. As rotinas matemáticas são operacionalizadas em uma planilha Excel de fácil manuseio.

A utilização do método deve estar vinculada às estratégias definidas no PEP e gerenciadas pelo BSC. A partir da definição para cada estratégia dos objetivos, metas e iniciativas, uma série de projetos pode ser elencada a fim de solucionar os problemas apresentados ou para alcançar as metas estabelecidas. O método permite a definição de critérios e a incorporação de valores ditos sociais, que guiarão a escolha ou a priorização de execução dos mesmos. Por exemplo, em relação ao fator crítico denominado criança e adolescência marginalizada pertencente à estrutura social da perspectiva social, um dos projetos para redução do percentual de crianças e adolescentes envolvidos em infrações pode ser o da implantação de uma granja comunitária que retire da rua as crianças e os adolescentes, amplie a renda familiar dos envolvidos e promova sua profissionalização e de seus familiares. Outro projeto pode ser a ampliação da estrutura de unidades correcionais. A priorização entre esses projetos será feita a partir da identificação dos critérios que norteiam o desenvolvimento das estratégias e das políticas urbanas adotadas pelos gestores a partir dos seguintes passos:

v estimativa da importância dos critérios - pontos em unidade de valor que levam em conta a importância relativa dos critérios e, assim, refletem os trade offs entre eles;

v cálculo dos valores dos projetos;

v priorização inicial dos projetos; 
v análise de robustez - feita através da variação dos coeficientes dos critérios, aleatoriamente e independentemente ao mesmo tempo, segundo uma função distribuição de probabilidade especificada pelo decisor;

v o último passo consiste na priorização final.

\section{Exemplificação em município de porte médio}

Em virtude de constituir-se em um sistema flexível e adaptar-se à realidade de qualquer cidade, a exemplificação poderia ter sido inteiramente fictícia. Entretanto optou-se por um exemplo real, mesmo que inúmeros procedimentos tenham que ter sido simulados, tendo em vista que uma situação conhecida forneceria melhores subsídios para as análises. A escolha por Passo Fundo ocorreu em função do acesso a inúmeros dados e por ter a cidade passado por um processo de planejamento recente que, após uma análise crítica sobre as diferenças entre ele e o processo de planejamento proposto (PEP), serviu de pano de fundo para as demais fases do sistema.

Cidade de porte médio do Rio Grande do Sul, Passo Fundo possuía, em 2000, uma população de 168.440 habitantes, sendo que, desses, 163.748 residiam na área urbana (IBGE, 2003). Com área total de $759,4 \mathrm{~km}^{2}$, área rural de 63.900 hectares e um perímetro urbano de aproximadamente $120 \mathrm{~km}^{2}$, dos quais em torno de $70 \mathrm{~km}^{2}$ encontram-se urbanizados, sua densidade média é de $221,8 \mathrm{hab} . / \mathrm{km}^{2}$.

O processo de planejamento que ocorreu durante o ano de 2000 no município de Passo Fundo foi analisado a partir de material coletado nas secretarias da prefeitura e de entrevista com diversos técnicos envolvidos na efetivação do Plano Diretor de Desenvolvimento Integrado (PDDI), com lideranças políticas e com representantes de entidades e associações da comunidade. $\mathrm{O}$ termo de referência (Prefeitura Municipal de Passo Fundo, PMPF, 2000) serviu como espinha dorsal para a análise, sendo a seguir apresentada uma síntese do documento.

Os objetivos gerais são aqueles referentes ao desenvolvimento de Passo Fundo e aos processos de administração e planejamento do município. São eles:

v promover o desenvolvimento integrado do município de Passo Fundo;

v propiciar a melhoria da qualidade de vida no que se refere a serviços e infra-estrutura públicos postos à disposição da comunidade; 
v propiciar o desenvolvimento das atividades produtivas urbanas e rurais, preservando o equilíbrio ambiental;

v garantir que a propriedade cumpra sua função social, atendendo as exigências fundamentais de ordenação da cidade e do município;

v racionalizar os investimentos do setor público através da participação comunitária na fixação das prioridades das políticas e programas a serem implantados;

v propor uma política de desenvolvimento para Passo Fundo.

Tendo em vista a impossibilidade de desencadear um processo de planejamento com todos os requisitos expostos pelo PEP sem uma decisão comunitária, a exemplificação do Sigau foi feita considerando como primeira fase o PDDI efetuado pela prefeitura e o planejamento estratégico implementado pelo Conselho de Desenvolvimento. A partir da escolha de algumas das estratégias geradas nos processos anteriormente citados, as fases seguintes do Sigau foram simuladas a fim de facilitar o entendimento da estrutura e da abrangência do sistema proposto.

Na exemplificação do Sigau foi considerada a premissa maior colocada pelo trabalho, tendo sido adotadas as perspectivas, os fatores críticos e os indicadores propostos no texto. As perspectivas observadas para o desenvolvimento sustentável foram a social, a ambiental, a físico-espacial e a econômica. A estratégia selecionada para desdobramento neste artigo foi garantir que a propriedade cumpra sua função social, atendendo as exigências fundamentais de ordenação da cidade e do município (o código designado para essa estratégia foi E1).

Foram simulados para a estratégia objetivos, metas e iniciativas. Também foram identificados fatores críticos e fontes de financiamento, como pode ser observado na planilha de acompanhamento do BSC. Os fatores críticos direcionaram a escolha pelos indicadores que oferecem subsídio para as análises pontuais e, ao mesmo tempo, alimentam o sistema de avaliação integrada.

Para exemplificar da utilização do MAL, a perspectiva social teve como objetivo promover o acesso à terra urbanizada desdobrado na meta de implantar cinco loteamentos de interesse social em áreas desocupadas dentro do perímetro urbano. 
Foram avaliadas diferentes áreas para a implantação dos loteamentos, cujos critérios utilizados para a priorização foram:

1. Distância da área ao Centro - 80

2. Número de domicílios previstos - 100

3. Recursos necessários para saneamento básico e energia elétrica -80

4. Recursos necessários para infra-estrutura viária -50

5. Distância da rede pública de ensino -80

6. Distância do atendimento ambulatorial -50

7. Proximidade de nascentes ou cursos d'água -50

8. Distância do local de origem -25

\begin{tabular}{|c|c|c|c|}
\hline \multicolumn{4}{|c|}{ Planilha de acompanhamento do BSC por estratégia } \\
\hline \multicolumn{4}{|c|}{$\begin{array}{l}\text { Estratégia E1: garantir que a propriedade cumpra sua função social, atendendo às exigências } \\
\text { fundamentais de ordenação da cidade e do município }\end{array}$} \\
\hline Perspectivas & Social & Físico-espacial & Econômica \\
\hline Objetivos & $\begin{array}{l}\text { Promover } 0 \text { acesso } \\
\text { à terra urbanizada }\end{array}$ & $\begin{array}{l}\text { Garantir usos sociais em } \\
\text { locais adequados da malha } \\
\text { urbana }\end{array}$ & $\begin{array}{l}\text { Gerar emprego e distribuição } \\
\text { de renda }\end{array}$ \\
\hline $\begin{array}{l}\text { Fatores } \\
\text { críticos }\end{array}$ & $\begin{array}{l}\text { Moradia, de forma regular, } \\
\text { em locais adequados e } \\
\text { integrados à malha urbana }\end{array}$ & $\begin{array}{l}\text { Ocupações ilegais em áreas } \\
\text { de risco }\end{array}$ & $\begin{array}{l}\text { Nível de emprego } \\
\text { Desenvolvimento setorial, } \\
\text { geração e distribuição de } \\
\text { renda }\end{array}$ \\
\hline Metas & \begin{tabular}{|l} 
Implantar um loteamento de \\
interesse social em áreas \\
desocupadas dentro do \\
perímetro urbano por ano
\end{tabular} & $\begin{array}{l}\text { Retirar as ocupações das } \\
\text { áreas de risco } \\
\text { Realocar as famílias até } \\
2005\end{array}$ & $\begin{array}{l}\text { Gerar } 500 \text { postos de trabalho } \\
\text { na construção civil (base da } \\
\text { pirâmide) até } 2005 \\
\text { Organizar uma cooperativa } \\
\text { de catadores de lixo até } \\
\text { agosto de } 2004\end{array}$ \\
\hline Iniciativas & $\begin{array}{l}\text { 1. Identificar áreas } \\
\text { passíveis de aplicação de } \\
\text { legislação específica para } \\
\text { utilização com loteamentos } \\
\text { populares } \\
\text { 2. Atualizar legislação } \\
\text { urbanística, incluindo a } \\
\text { demarcação das zonas de } \\
\text { uso especiais para fins de } \\
\text { habitação de interesse social }\end{array}$ & $\begin{array}{l}\text { 1. Cadastrar as famílias e } \\
\text { avaliar a estrutura social dos } \\
\text { agrupamentos } \\
\text { 2. Implementar infra- } \\
\text { estrutura nas áreas } \\
\text { escolhidas para realocação } \\
\text { das famílias } \\
\text { 3. Construir as unidades } \\
\text { habitacionais }\end{array}$ & $\begin{array}{l}\text { 1. Financiar a construção de } \\
\text { mil unidades habitacionais } \\
\text { 2. Criar incentivos fiscais } \\
\text { para a implantação de } \\
\text { empreendimentos que gerem } \\
\text { empregos } \\
\text { 3. Destinar área para a } \\
\text { construção de uma } \\
\text { cooperativa para catadores } \\
\text { de lixo }\end{array}$ \\
\hline
\end{tabular}




\begin{tabular}{|c|c|c|c|}
\hline Perspectivas & Social & Físico-espacial & Econômica \\
\hline $\begin{array}{l}\text { Indicadores } \\
\text { (os } \\
\text { indicadores } \\
\text { serão } \\
\text { acompanhados } \\
\text { pela planilha } \\
\text { específica de } \\
\text { indicadores } \\
\text { que alimenta a } \\
\text { avaliação } \\
\text { integrada da } \\
\text { sustentabilida- } \\
\text { de urbana) }\end{array}$ & $\begin{array}{l}\text { Pressão: crescimento } \\
\text { populacional, insuficiência } \\
\text { média de renda familiar } \\
\text { Estado: déficit habitacional, } \\
\text { número de domicílios em } \\
\text { favelas ou assemelhados } \\
\text { (cortiços, divisão de lotes), } \\
\text { número de loteamentos } \\
\text { irregulares, distância dos } \\
\text { loteamentos populares ao } \\
\text { Centro (ou centro de } \\
\text { bairros), número de } \\
\text { pessoas sem moradia } \\
\text { vivendo em áreas públicas, } \\
\text { percentual de população } \\
\text { que vive em domicílios } \\
\text { com densidade média } \\
\text { acima de duas pessoas por } \\
\text { dormitório, percentual da } \\
\text { população que vive em } \\
\text { domicílios duráveis } \\
\text { Resposta: montante de } \\
\text { recursos aplicados em } \\
\text { financiamentos de } \\
\text { habitações e loteamentos } \\
\text { populares, existência de } \\
\text { programas de urbanização } \\
\text { de favelas, número de } \\
\text { moradias produzidas com } \\
\text { financiamentos concedidos } \\
\text { a empresas, cooperativas } \\
\text { populares, associações } \\
\text { populares }\end{array}$ & $\begin{array}{l}\text { Pressão: taxa de } \\
\text { urbanização, expansão fora } \\
\text { do perímetro urbano, } \\
\text { percentual da população } \\
\text { vivendo abaixo da linha de } \\
\text { pobreza } \\
\text { Estado: número de } \\
\text { habitações/pessoas } \\
\text { morando em áreas de risco, } \\
\text { número de habitações/ } \\
\text { pessoas morando em áreas } \\
\text { irregulares, número de } \\
\text { loteamentos irregulares e } \\
\text { clandestinos } \\
\text { Resposta: existência e } \\
\text { abrangência de políticas de } \\
\text { reestruturação da } \\
\text { propriedade e uso do solo } \\
\text { urbano, existência de } \\
\text { programas de prevenção à } \\
\text { ocupação de áreas de risco, } \\
\text { número de beneficiados por } \\
\text { programas de regularização } \\
\text { fundiária }\end{array}$ & $\begin{array}{l}\text { Pressão: população } \\
\text { economicamente ativa, } \\
\text { composição setorial do PIB, } \\
\text { taxa de desemprego, índice } \\
\text { de concentração de renda, } \\
\text { percentual de pobres, } \\
\text { percentual de pessoas com } \\
\text { RFPC abaixo de 0,5 SM } \\
\text { Estado: rendimento médio } \\
\text { mensal, taxa de atividade, } \\
\text { taxa de desocupação, índice } \\
\text { de Gini, pessoal ocupado de } \\
\text { empresas com CGC, por } \\
\text { setor de atividade, grau de } \\
\text { desigualdade, insuficiência } \\
\text { média de renda, composição } \\
\text { setorial do PIB, percentual de } \\
\text { pessoas ocupadas em } \\
\text { empresas com CGC por setor } \\
\text { de atividade, renda familiar } \\
\text { per capita média } \\
\text { Resposta: investimentos em } \\
\text { infra-estrutura e incentivos } \\
\text { fiscais nos setores } \\
\text { produtivos, de serviço, } \\
\text { cultural e de saúde, de fluxo } \\
\text { de investimento público, } \\
\text { regularidade de fluxo de } \\
\text { investimento privado, ações } \\
\text { para efetivação da reforma } \\
\text { agrária, incentivo à } \\
\text { agricultura familiar, reforma } \\
\text { trabalhista, programas de } \\
\text { microcrédito e incentivos } \\
\text { fiscais }\end{array}$ \\
\hline $\begin{array}{l}\text { Fontes de } \\
\text { financiamento }\end{array}$ & $\begin{array}{l}\text { CEF — programas: Gestão } \\
\text { Urbana, Morar Melhor, Pró- } \\
\text { Moradia, Pró-Infra, PAT — } \\
\text { Prosanear/Bird } \\
\text { BNDES - Programa de } \\
\text { Desenvolvimento Urbano }\end{array}$ & $\begin{array}{l}\text { CEF — programas: Gestão } \\
\text { Urbana, Morar Melhor } \\
\text { BNDES — Programa de } \\
\text { Desenvolvimento Urbano }\end{array}$ & $\begin{array}{l}\text { CEF — programas: Prodec, } \\
\text { Pró-Moradia, Pró- } \\
\text { Saneamento } \\
\text { BNDES - SGPC } \\
\text { Ministério da Ação Social — } \\
\text { Programa Geração de Renda } \\
\text { MEC — Projeto Alvorada }\end{array}$ \\
\hline
\end{tabular}

Rap Rio de Janeiro 40(5):809-40, Set./Out. 2006 
A partir da primeira definição dos critérios, dos valores e dos pesos, as rotinas matemáticas, conforme descrito na fundamentação teórica e implementadas pela planilha Excel, promovem o cálculo do desempenho das áreas perante cada critério, a análise de robustez e a priorização final. As áreas 2 e 3 foram as que apresentaram melhor desempenho ante os critérios estabelecidos (figura 9).

Figura 9 Priorização final das áreas para implantação de
loteamento popular

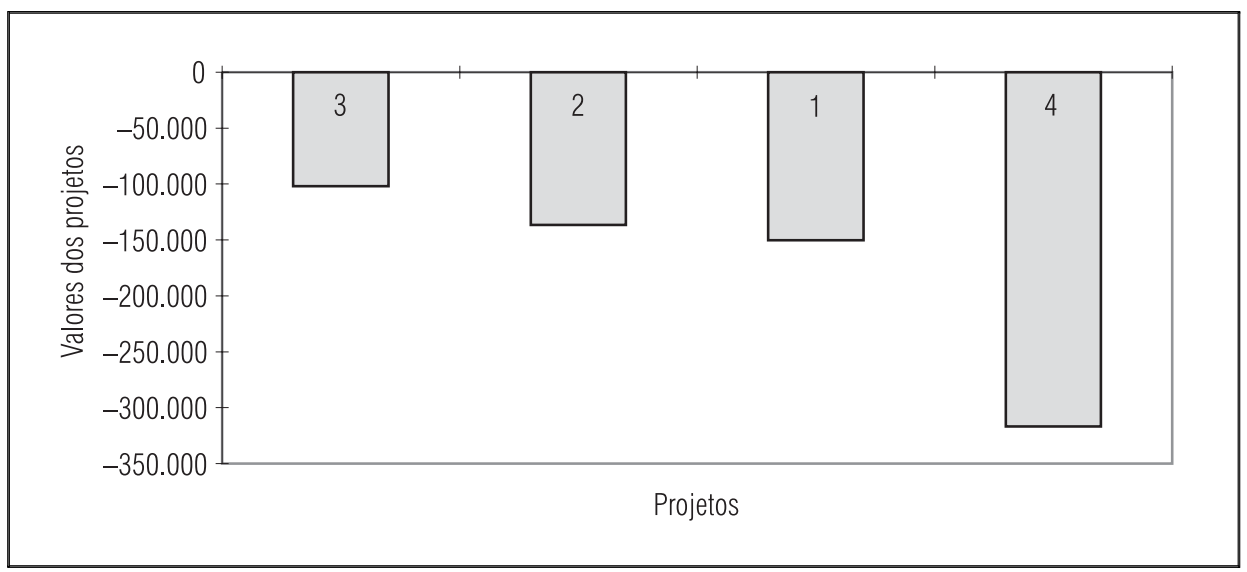

Cabe salientar que em um primeiro momento somente foram avaliadas áreas pertencentes ao poder público e em locais com vocação residencial. Assim, não foi considerado o critério custo da terra. Caso a prefeitura considere também a possibilidade de aquisição de áreas, o que poderá ocorrer para as próximas implantações, esse novo critério deverá ser incluído ou substituir um dos existentes.

Para a avaliação integrada, devido à dimensão da tarefa de levantamento de dados, que deverá ser obrigatoriamente efetuada envolvendo inúmeras equipes de trabalho, e demonstrando que a estrutura proposta permite um crescimento a partir do desenvolvimento das capacidades institucionais de cada município, algumas informações foram coletadas em diversos bancos de dados, outras o foram in loco, umas foram estimadas, e outras deixadas em branco, situação que poderá ocorrer na realidade.

Deve ficar claro que o objetivo da exemplificação não foi avaliar a condição real de sustentabilidade do município, mas a utilização do Sigau em condições mais próximas da realidade, visando identificar as dificuldades.

O resultado obtido, que está disponível em Rossetto (2003) através dos indicadores coletados e estimados, foi o de que o município de Passo Fundo 
encontra-se em uma situação ainda bastante incipiente de desenvolvimento sustentável (figura 10).

O pior desempenho apresentado foi o da perspectiva físico-espacial, e seu fator crítico mais deficiente foi a organização físico-espacial. Entretanto, ao se avaliar a planilha de indicadores compostos de segundo nível, observase que o resultado pode ser explicado em função do baixo desempenho em todos os fatores críticos.

Já a perspectiva social, embora tenha ficado com um indicador levemente superior, seus indicadores compostos de segundo nível demonstram que alguns fatores críticos estão com pior desempenho, como, por exemplo, segurança pública, lazer e inclusão territorial. Esses fatores foram compensados pelo desempenho da saúde, da educação e da cultura. Seu melhor desempenho foi apresentado na perspectiva econômica, no fator crítico economia local.

Figura 10

\section{Estado atual da sustentabilidade de Passo Fundo}

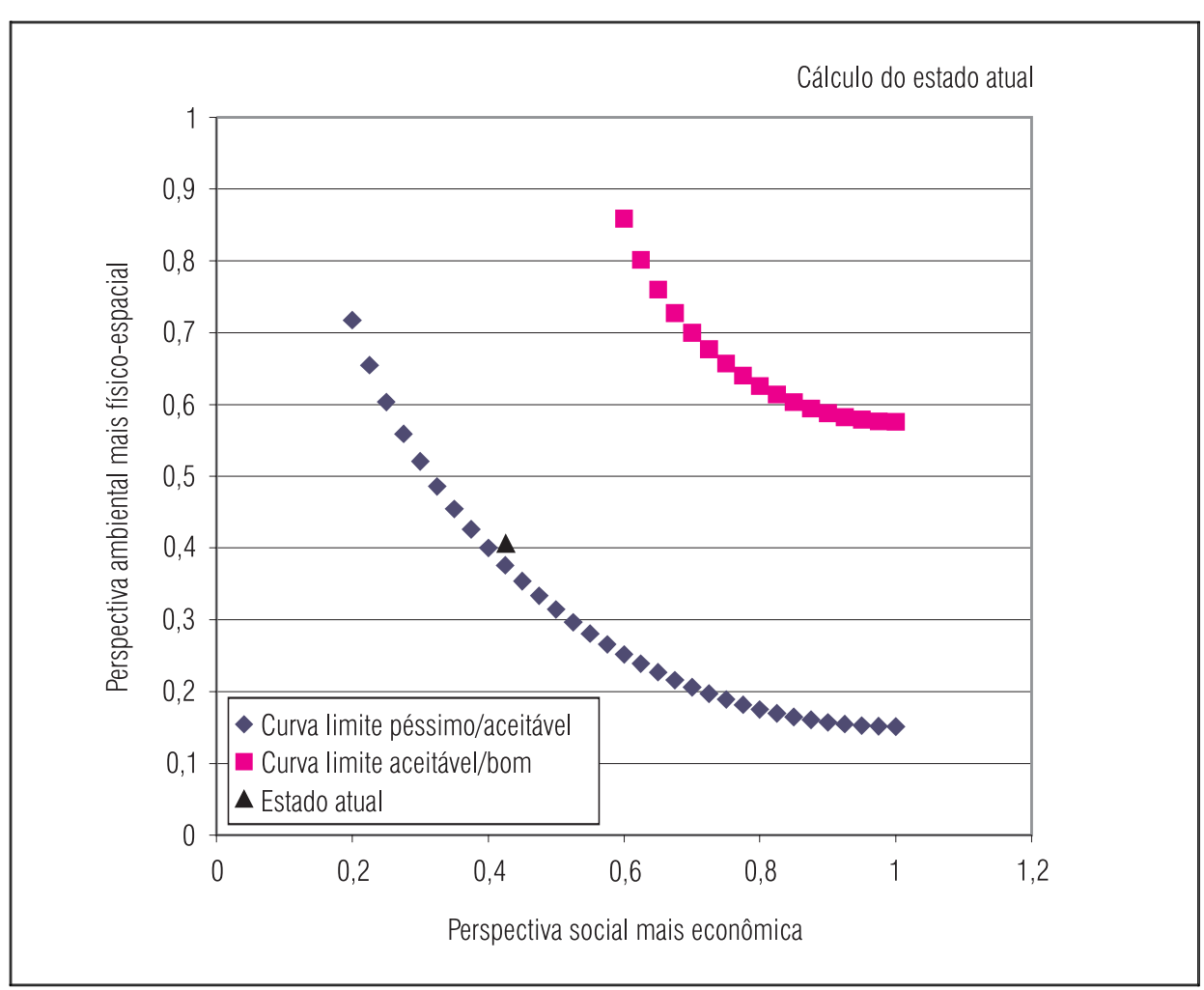


O sistema permite ainda que as avaliações sejam desdobradas para os indicadores de segundo nível e indicadores básicos, fornecendo um rico material de análise.

Ao se utilizar o sistema em Passo Fundo ficou evidente a desarticulação das informações geradas pelos diversos órgãos. A atualização dos dados variou entre 1996 e 2003, as unidades de análise não se sobrepuseram (o IBGE e a PMPF utilizam distintas divisões setoriais) e alguns dados, necessários para exemplificar os fatores críticos para cada perspectiva, tiveram que ser coletados, como, por exemplo, as condições ambientais e a interferência da urbanização no microclima.

\section{Conclusões}

O presente artigo foi motivado pela necessidade de alteração das práticas atuais de planejamento e gestão de espaços urbanos. A problemática apresentada na realidade brasileira assume proporções assustadoras, visto que se propagam de forma geométrica os problemas sociais e ambientais na grande maioria das cidades, independentemente de seu porte ou nível de desenvolvimento.

Criar um caminho que melhore o processo decisório na gestão municipal de forma a possibilitar o aumento da qualidade do ambiente urbano foi o que direcionou o desenvolvimento deste artigo. A utilização de um BSC observando as perspectivas social, ambiental, físico-espacial e econômica de forma integrada representa um avanço no processo decisório, esse voltado à busca pelo desenvolvimento sustentável. Essa observação feita a partir de uma estrutura de indicadores baseada em um sistema de pressão-estado-resposta fornece os subsídios necessários para uma avaliação integrada do panorama da cidade, avaliação essa de fundamental importância para as escolhas coletivas.

Uma contribuição bastante significativa em termos de operacionalização da avaliação do desenvolvimento da cidade é o instrumento que se baseou na metodologia proposta pela Unep/Unesco, cuja integração de indicadores de diferentes perspectivas e sua composição em níveis sucessivos garantem uma análise abrangente da situação em que se encontra a cidade a partir dos parâmetros que a própria comunidade estabelecer como limites para cada questão. A possibilidade de avaliar cenários para cada uma dessas questões disponibiliza um rico material de trabalho e de comunicação.

Com este instrumento, a transparência e a facilidade de comunicar a posição da cidade auxiliam na condução dos trabalhos de planejamento e fornecem credibilidade aos trabalhos de gestão. A flexibilidade do sistema possibilita que as características de cada município sejam consideradas desde a 
escolha das perspectivas a serem observadas, que aceitam desdobramentos ou subtrações, desenhando o perfil da cidade até a escolha dos indicadores. O artigo propõe uma sistemática de escolha de indicadores considerados importantes para o desenvolvimento sustentável, os quais devem ser adaptados a cada caso, pois sua própria escolha já direciona a comunidade para seus objetivos maiores. Cabe salientar que este artigo recomenda a manutenção no mínimo dos indicadores que direcionam ações para a busca da justiça social e do equilíbrio ecológico, correndo o risco, em caso contrário, de o desenvolvimento tornar-se sustentável somente no rótulo.

A definição dos parâmetros e pesos da etapa de avaliação integrada da sustentabilidade urbana demanda estudos interdisciplinares, definindo intervalos aceitáveis de oscilação das prioridades, de modo a não distorcer o objetivo maior do trabalho, que é direcionar o crescimento de forma sustentável, ou seja, com equilíbrio entre as perspectivas.

Por último, ao se propor um método de priorização de projetos, que pode ser substituído por outros mais elaborados e complexos à medida que as equipes aprimoram suas capacidades técnicas, fecha-se o ciclo do processo decisório, viabilizando que os projetos sejam escolhidos a partir das estratégias maiores, definidas pela comunidade e ratificadas pelos gestores e agentes públicos e privados que irão efetivá-las. Embora desempenhem a importante tarefa de direcionar e equilibrar as ações de planejamento e gestão, os instrumentos escolhidos para as três fases do Sigau são de fácil operacionalização e compreensão, buscando viabilizar sua utilização em qualquer município da rede urbana brasileira.

Outros estudos indicados para a continuidade das proposições sobre a aplicabilidade do sistema são o de sua utilização no formato de municípios consorciados de uma região, na perspectiva da retomada do planejamento regional ou de utilização em regiões metropolitanas e aglomerados urbanos e no âmbito de bacia hidrográfica.

Considerando o delicado momento por que passa a rede urbana brasileira, no qual a mudança das práticas de planejamento e de gestão está condicionada ao total colapso das cidades, o sistema proposto encaminha uma nova postura ao enfocar as questões que interagem no espaço urbano de forma integrada e incorporar os conceitos de sustentabilidade. As próprias mudanças no cenário nacional apontam para uma maior autonomia dos municípios e, ao mesmo tempo, maior articulação entre municípios se solidarizando em forma de consórcios, como contra a tendência à guerra fiscal, em novas formas de organização supramunicipal no marco da busca de um novo pacto federativo. Em contrapartida aumenta a responsabilidade em gerir seus próprios destinos, ambiente propício para a mudança de paradigmas. 
E, por fim, em relação à utilização do sistema, recomenda-se que um processo de planejamento consolidado em bases participativas seja o direcionador das estratégias, que todo o sistema seja uma conquista coletiva e que seja utilizado para aumentar a transparência das ações públicas. Que cada comunidade procure incorporar suas características peculiares, mas que preserve como seu maior objetivo a melhoria efetiva da qualidade de vida das populações de forma justa e equilibrada e que o desenvolvimento seja garantido para todos.

\section{Referências bibliográficas}

BEZERRA, M. do C.; FERNANDES, M. A. (Coords.). Cidades sustentáveis: subsídios à elaboração da Agenda 21 brasileira. Brasília: Ministério do Meio Ambiente, Instituto Brasileiro do Meio Ambiente e dos Recursos Naturais Renováveis, Consórcio Parceria 21 Ibam-IserRedeh, 2000.

BOLLMANN, H. A. Metodologia para avaliação ambiental integrada. In: MAIA, N. B.; MARTOS, H. L.; BARRELLA, W. (Orgs.). Indicadores ambientais: conceitos e aplicações. São Paulo: Educ/Comped/Inep, 2001.

; MARQUES, D. da M. Gestão ambiental integrada de bacias hidrográficas: bacia do rio Cachoeiras - São Mateus do Sul-PR. Revista Brasileira de Recursos Hídricos, v. 6, n. 3, p. $45-65$, jul./set. 2001.

BRAMONT, P. P. B. Priorização de projetos sob a ótica social: um método envolvendo análise de múltiplos critérios. 1996. Tese (Doutorado em Engenharia de Produção) — Programa de Pós-Graduação em Engenharia de Produção, Universidade Federal de Santa Catarina, Florianópolis, 1996.

BRINDLEY, T. et al. Remaking planning. The politics of urban change in the Thatcher years. Londres: Unwing Hyman, 1989.

EPA (ENVIRONMENTAL PROTECTION AGENCY). Committee to review the EPA's Environmental Monitoring and Assessment Programs. Review of EPA's Environmental Monitoring and Assessment Program: overall evaluation. Washington, DC: National Academy Press, 1995.

IBGE (INSTITUTO BRASILEIRO DE GEOGRAFIA E ESTATÍSTICA). Resultados do Censo de 2000. Disponível em: <www.ibge.gov.br>. Acesso em: 21 jan. 2003.

KAPLAN, R. S.; NORTON, D. P. A estratégia em ação: balanced scorecard. Tradução de Luiz Euclides Trindade Frazão Filho. Rio de Janeiro: Campus, 1997.

MATUS, C. Política, planejamento e governo. 2. ed. Brasília: Ipea, 1996. 
MORAES, F. B. de. Exclusão e inclusão: delimitação e permeabilidade dos territórios. In: DEL RIO, V; DUARTE, C.; RHEINGANTZ, P. Projeto do lugar. Rio de Janeiro: Contra Capa, 2002.

OECD. Core set of indicators for environmental performance reviews: a synthesis report by the Group on the State of the Environment. Paris: OECD, 1993. Disponível em: < www. oecd.org >. Acesso em: fev./jul. 2001.

PMPF (PREFEITURA MUNICIPAL DE PASSO FUNDO). Termo de Referência do Plano Diretor Integrado de Passo Fundo/RS. 2000.

RHEINGANTZ, P. A. Pequena digressão sobre conforto ambiental e qualidade de vida nos centros urbanos. Revista Ciência \& Ambiente, v. 1, n. 1, p. 36-58, jul. 1990.

ROLNIK, R. Regulação urbanística e exclusão territorial. Revista Polis, n. 32, 2000.

; CYMBALISTA, R. Instrumentos urbanísticos contra a exclusão social. Revista Polis, n. 29, 1997.

ROSSETTO, A. M. Proposta de um sistema integrado de gestão do ambiente urbano (Sigau) para o desenvolvimento sustentável de cidades. 2003. 423 f. Tese (Doutorado em Engenharia de Produção) - Programa de Pós-Graduação em Engenharia de Produção, Universidade Federal de Santa Catarina, Florianópolis, 2003.

SACHS, I. Ecodesenvolvimento: crescer sem destruir. São Paulo: Vértice, 1986.

SOUZA, M. L. de. Mudar a cidade: uma introdução crítica ao planejamento e à gestão urbanos. 2. ed. Rio de Janeiro: Bertrand Brasil, 2003.

UNEP/UNESCO. Methodological guidelines for the integrated environmental evaluation of water resources development. Paris: Unesco, 1987.

Rap Rio de Janeiro 40(5):809-40, Set./Out. 2006 